60, 1236 (1964).

3) Hirato, M. and S. Yoshioka: Sekiyu Gakkaishi (J. Japan Petrol. Inst.), 15, 818 (1972)

4) Hirato, M. and S. Yoshioka: Int. Chem. Eng., 13, 347 (1973).

5) Kerr, J. A. and A. F. Trotman-Dickenson: J. Chem. Phys., 19, 163 (1951).

6) Murata, M., S. Saito, A. Amano and S. Maeda: J. Chem. Eng. Japan, 6, 252 (1973).

7) Murata, M., N. Takeda and S. Saito: ibid., 7, 286 (1974).
8) Murata, M. and S. Saito: ibid., 7, 389 (1974).

9) Murata, M. and S. Saito: ibid., 8, 39 (1975).

10) Tanaka, S., Y. Arai and S. Saito: ibid., 8, 305 (1975).

11) Tanaka, S., Y. Arai and S. Saito: ibid., 9, 161 (1976).

12) Tsang, W.: Int. J. Chem. Kinetics, 1, 245 (1969).

(A part of this paper was presented at the 39th Annual Meeting of The Soc. of Chem. Engrs., Japan, at Kobe, April, 1974.)

\title{
HYDROGENATION OF ETHYLENE IN TWO DIMENSIONAL GAS-SOLID FLUIDISED BED WITH PERFORATED PLATE
}

\author{
Ryozo TOEI, Morihiro OICHI, Hisataka HAYASHI, \\ KIYOKAZU KUBO, TOSHIHIRO YANAGIDA \\ AND RYUICHI MATSUNO \\ Department of Chemical Engineering, Kyoto University, Kyoto 606
}

\begin{abstract}
A fairly rapid chemical reaction, i.e., hydrogenation of ethylene by palladium catalyst, was carried out at a room temperature in a two dimensional fluidised bed with a perforated plate distributor. The results were considerably affected by the behaviour of the bed near its bottom. The measured hydrogen conversion was compared with that predicted by the so-called "coalescence model". Consistency of the experimental and calculated results was fairly good.

The significance of various parameters included in the model was also investigated. The parameters examined were the gas interchange coefficients, the volume fraction of particles in the bubble, and the gas flow rate as bubbles.

In conclusion, it was pointed out that the deviation of gas flow rate as bubbles from that predicted by the two phase theory at the bottom of bed affected significantly the conversion of a rapid chemical reaction.
\end{abstract}

\section{Introduction}

Many models ${ }^{4,6,9,10,12,15-18,22,24,27,28,37)}$ based on the behaviour of bubbles have been proposed and analyses for transport phenomena, catalytic chemical reactions, etc. in a gas fluidised bed have been developed. It can be said that the general features of fluidised beds were elucidated by these models.

Future work should be directed towards the improvement of these models in order to be able to express the influence of distributor ${ }^{1-3,7,38)}$ and bed diameter ${ }^{7,14}$ on the performances of the fluidised bed.

Conclusions deduced from the investigations so far reported $^{1-3,5,7,9,20,21,23,34,35,38)}$ as to the behaviour of the bed just above a distributor was that there were, in the case of perforated plate, the formation of jet above a hole, the formation of bubble just above the jet and the growth of bubbles by successive coalescence.

Received on August 27, 1976. Correspondence concerning this article should be addressed to R. Toei. M. Oichi is now with Teijin, Ltd., Osaka 541. H. Hayashi is now with Kanegafuchi Chemical Ind., Ltd., Settsu City 567. R. Matsuno is at Dept. of Food Science and Technology, Kyoto University, Kyoto 606.
Through the observations ${ }^{34,35)}$ in a two dimensional bed with a perforated plate, besides the above phenomena, it was recognized that the gas flow rate in the continuous phase was greater ${ }^{31}$ than that predicted from the two phase theory ${ }^{36}$ under certain experimental conditions.

The purpose of the present paper is to investigate how the behaviour of bed at the bottom affects the performance of a fairly rapid catalytic chemical reaction.

\section{Experimental}

Hydrogenation of ethylene by palladium catalyst in $\mathrm{C}_{2} \mathrm{H}_{4}$-rich circumstance was employed as the reaction system.

$$
\mathrm{C}_{2} \mathrm{H}_{4}+\mathrm{H}_{2} \longrightarrow \mathrm{C}_{2} \mathrm{H}_{6}
$$

The physical properties of the catalyst are shown in Table 1. The reaction was performed in the presence of the large amount of inert gas $\mathrm{N}_{2}$. This reaction system is -0.03 th order ${ }^{29}$ and the first order with respect to $\mathrm{C}_{2} \mathrm{H}_{4}$ and $\mathrm{H}_{2}$ concentrations, respectively. 
Table 1 Palladium catalyst

\begin{tabular}{cccccc} 
Carrier & $\begin{array}{c}\text { Particle } \\
\text { size }\end{array}$ & $\begin{array}{c}\mathrm{wt} \% \text { of } \\
\mathrm{Pd}\end{array}$ & $\begin{array}{c}\rho_{p} \\
{[\mathrm{~g} / \mathrm{cc}]}\end{array}$ & $\begin{array}{c}u_{m f} \\
{[\mathrm{~cm} / \mathrm{sec}]}\end{array}$ & $\begin{array}{c}\varepsilon_{m f} \\
{[-]}\end{array}$ \\
\hline $\begin{array}{c}\text { Alumina } \\
\text { particles }\end{array}$ & $60-80^{*}$ & 0.002 & 1.51 & 2.46 & 0.44 \\
\hline
\end{tabular}

Table 2 Two dimensional fluidised bed reactor

Fluidised bed

Height

Thickness

Width

Material

Perforated plate

Number of holes 20

Diameter of holes $\quad 0.1 \mathrm{~cm}$

Thickness

$1.0 \mathrm{~cm}$

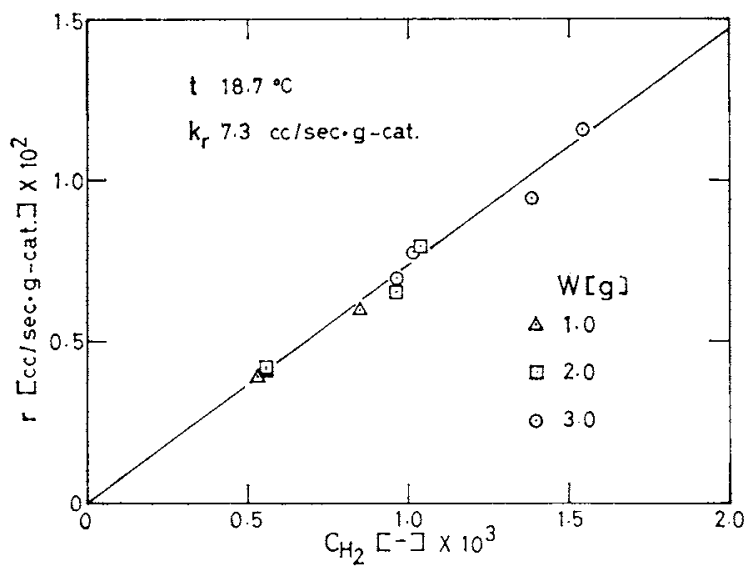

Fig. 1 Relation between hydrogen concentration and chemical reaction rate in packed bed reactor

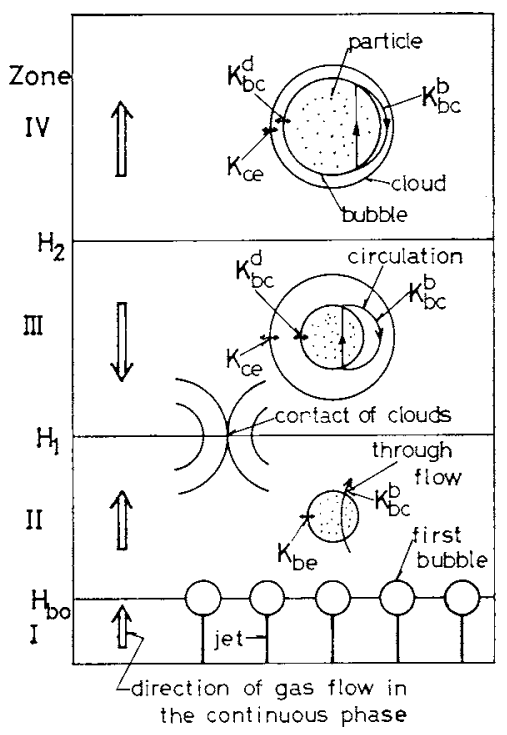

Fig. 2 Schematic illustration of model

The first order reaction rate constant was measured in a packed bed reactor $\left(14.4^{\dot{\phi}} \times 100\right)$ made of stainless steel and was used for the analysis of the reaction performance in a two dimensional fluidised bed reactor with a perforated plate distributor shown in Table 2. The fluidised bed has almost the same di-
Table 3 Experimental condition and result

$t=20.2^{\circ} \mathrm{C}, k_{r}=8.7 \mathrm{cc} / \mathrm{sec} \cdot \mathrm{g}$-cat, $K_{r}=13.11 / \mathrm{sec}$

\begin{tabular}{|c|c|c|c|c|c|c|}
\hline $\begin{array}{c}u_{0} \\
{[\mathrm{~cm} / \mathrm{sec}]}\end{array}$ & $\begin{array}{l}C_{\mathrm{H}_{2}} \\
{[-]}\end{array}$ & $\begin{array}{c}C_{\mathrm{C}_{2} \mathrm{H}_{4}} \\
[-]]^{4}\end{array}$ & $\begin{array}{l}C_{\mathrm{N}_{2}} \\
{[-]}\end{array}$ & $\begin{array}{l}H_{m f} \\
{[\mathrm{~cm}]}\end{array}$ & {$\left[\begin{array}{c}x \\
-1\end{array}\right]$} & $\begin{array}{c}K_{r}^{\prime} \\
{[--]}\end{array}$ \\
\hline \multirow[t]{4}{*}{5.85} & $0.61 \times 10^{-3}$ & $2.47 \times 10^{-2}$ & 0.975 & 1.62 & 0.438 & 2.02 \\
\hline & 2.87 & 2.74 & 0.970 & 2.72 & 0.587 & 3.40 \\
\hline & 3.03 & 2.34 & 0.975 & 5.40 & 0.823 & 6.72 \\
\hline & 3.06 & 2.65 & 0.971 & 7.35 & 0.874 & 9.18 \\
\hline \multirow[t]{5}{*}{8.6} & 2.11 & 1.78 & 0.980 & 1.39 & 0.277 & 1.18 \\
\hline & 0.407 & 1.65 & 0.983 & 1.48 & 0.346 & 1.26 \\
\hline & 2.11 & 1.65 & 0.981 & 3.70 & 0.599 & 3.14 \\
\hline & 4.18 & 1.72 & 0.983 & 7.40 & 0.748 & 6.27 \\
\hline & 2.06 & 1.88 & 0.980 & 9.80 & 0.828 & 8.34 \\
\hline \multirow[t]{4}{*}{15.0} & 1.23 & 1.04 & 0.989 & 3.05 & 0.485 & 1.48 \\
\hline & 0.257 & 1.10 & 0.989 & 4.80 & 0.628 & 2.34 \\
\hline & 0.257 & 1.01 & 0.990 & 7.10 & 0.743 & 3.46 \\
\hline & 1.29 & 1.02 & 0.989 & 10.0 & 0.780 & 4.87 \\
\hline
\end{tabular}

mension as the one in which physical behaviour was observed $^{34,35)}$ and the arrangement of the holes in the perforated plate was on a line.

The sampled gas at the exit of the reactor was analysed by gas chromatography and the conversion of $\mathrm{H}_{2}$ gas was determined.

The reaction conditions in the packed bed reactor were $Q_{T}=10-12 \mathrm{cc} / \mathrm{sec}$, mole fraction of $\mathrm{H}_{2}$ gas $5 \times 10^{-4}-1.6 \times 10^{-3}$, that of $\mathrm{C}_{2} \mathrm{H}_{4}$ gas $1 / 20-1 / 30$, $W=1-3 \mathrm{~g}$ and temperature $18.7-29.1^{\circ} \mathrm{C}$.

The first order reaction rate constant $k_{r}$ is given by

$$
\begin{aligned}
& -Q_{T} d C_{\mathrm{H}_{2}}=r d W=k_{r} C_{\mathrm{H}_{2}} d W \\
& k_{r}=-\left(Q_{T} / W\right) \ln (1-\chi)
\end{aligned}
$$

The relation between $C_{\mathrm{H}_{2}}$ and reaction rate $r$ shown in Fig. 1 clearly shows that this reaction is first order with respect to $C_{\mathrm{H}_{2}}$. The $k_{r}$ given by Fig. 1 is 7.3 $\mathrm{cc} / \mathrm{sec} \cdot \mathrm{g}$-cat. at $18.7^{\circ} \mathrm{C}$. The apparent activation energy was obtained as $17.1 \mathrm{kcal} / \mathrm{mol}$ from the Arrhenius plot.

Experiments in the fluidised bed were carried out at $20.2^{\circ} \mathrm{C}$ where $k_{r}$ was $8.7 \mathrm{cc} / \mathrm{sec} \cdot \mathrm{g}$-cat. and $K_{r}$, $13.11 / \mathrm{sec}$. The experimental conditions and the results are shown in Table 3 .

\section{Theoretical}

The experimental results with the fluidised bed were compared with the calculated results from the socalled "coalescence model" ${ }_{4,6,12,24,28,37)}$, i.e., the model which takes into account the change of the bubble size along the bed height.

It is assumed that a gas introduced into the fluidised bed passes through three phases, i.e., bubble, cloud and continuous phases, by plug flow. Furthermore the bed is divided into four zones along the height as shown in Fig. 2.

In the first zone, a jet is formed just above the distributor and the first bubble is generated at $H_{b 0}$. There are two phases, i.e., the jet phase (the bubble 
phase) and the continuous phase.

The second zone starts from $H_{b 0}$. At $H_{b 0}, \alpha$ is less than 1 and no cloud is formed. As the consequence of the successive bubble coalescence, $u_{b}$ increases, $\alpha$ exceeds unity, and eventually cloud formation occurs. But, if $\alpha$ is close to unity, the cloud diameter is too large and exceeds the bed width. Thus, a height $H_{1}$ is defined as the height where the cloud of existing bubble contacts each other. The second zone ends at $H_{1}$. The bubble and cloud phases must be considered.

In the third zone, the bubble, cloud and continuous phases are considered. Because of the large size of the cloud, the sum of gas flow rates as bubbles and clouds exceeds the total flow rate $Q_{T}$ and the gas in the continuous phase flows downward. As the consequence of bubble coalescence, the ratio of the cloud volume to the bubble volume decreases because the bubble velocity increases. Then, the downward flow rate in the continuous phase decreases to zero at a height $H_{2}$.

In the fourth zone, the gas in the continuous phase flows upward.

Observations $^{31,34,35)}$ in a two dimensional bed showed that, under certain experimental conditions, the gas flow rate as bubbles near the bottom of the bed was smaller than that predicted from the two phase theor $y^{36)}$, and gradually increased with the bed height up to the theoretical value. This change causes the change in the gas flow rate as clouds since clouds are accompanied by bubbles. Eventually, the gas flow rate through the continuous phase changes because the total gas flow rate must be conserved. The gas flow rate as clouds and that through the continuous phase also change with the increase of bubble size by the coalescence of bubble because it increases the bubble velocity and then, decreases the ratio of the cloud volume to the bubble volume. These variations of flow rates must be taken into account for the formulation of basic differential equations.

\section{1 Basic equation}

1) The first zone The concentration of the reactant gas at $H_{b 0}$ is given by

$$
\begin{gathered}
C_{b}=C_{i n} \\
C_{e}=C_{i n} \exp \left[-K_{r}\left(1-\varepsilon_{m f}\right) H_{b 0} / u_{m f}^{\prime}\right]
\end{gathered}
$$

where $u_{m f}^{\prime}=\left(Q_{T}-Q_{b}\right) / A \geqq u_{m j}$. In the two equations, the following assumptions are implied.

1) the jet volume is negligible;2) no catalyst in the jet; 3) no gas interchange between the jet and continuous phases. A comment on assumption 3) will be made in section 3 .

2) The second zone

Continuous phase,

$$
\begin{aligned}
Q_{e} d C_{e} / d h= & K_{b e}\left(C_{b}-C_{e}\right) \delta_{b} A-K_{r} C_{e}\left(1-\delta_{b}\right)\left(1-\varepsilon_{m f}\right) A \\
& -C_{e} d Q_{e} / d h-\left(-C_{e} d Q_{e} / d h\right)
\end{aligned}
$$

Bubble phase,

$$
\begin{aligned}
Q_{b} d C_{b} / d h= & -K_{b e}\left(C_{b}-C_{e}\right) \delta_{b} A-K_{r} C_{b} \delta_{b} \gamma_{p} A \\
& -C_{b} d Q_{b} / d h+C_{e} d Q_{b} / d h
\end{aligned}
$$

The last terms on the right hand side of Eqs. (5) and (6) show the decrease and increase of the reactant gas in the continuous phase and in the bubble phase, respectively, caused by the increase of the gas flow rate as bubbles along the bed height. Note that $d Q_{b} / d h=-d Q_{e} / d h$ and $K_{b e}=K_{b e}$ in this zone.

Equations (5) and (6) are solved numerically by the step wise method.

3) The third zone

Continuous phase,

$$
\begin{gathered}
Q_{e} d C_{e} / d h=K_{c e}\left(C_{e}-C_{e}\right) \delta_{b} A-K_{r} C_{e}\left[1-\delta_{b}(1+\beta)\right] \\
\times\left(1-\varepsilon_{m f}\right) A-C_{e} d Q_{e} / d h+C_{e} d Q_{e} / d h
\end{gathered}
$$

Cloud phase,

$$
\begin{aligned}
& Q_{e} d C_{c} / d h=K_{b c}\left(C_{b}-C_{c}\right) \delta_{b} A-K_{c e}\left(C_{c}-C_{e}\right) \delta_{b} A \\
& \quad-K_{r} C_{c} \delta_{b} \beta\left(1--\varepsilon_{m f}\right) A-C_{c} d Q_{c} / d h-\left(-C_{c} d Q_{c} / d h\right)
\end{aligned}
$$

Bubble phase,

$$
\begin{aligned}
Q_{b} d C_{b} / d h= & -K_{b c}\left(C_{b}-C_{c}\right) \delta_{b} A-K_{r} C_{b} \delta_{b} \gamma_{p} A \\
& -C_{b} d Q_{b} / d h+C_{c} d Q_{b} / d h
\end{aligned}
$$

Since the gas in the continuous phase descends, the change in $C_{e}$ along the height is discontinuous at $H_{1}$. By assuming $C_{e}$ at $H_{1}, C_{e}$ is determined by mass balance, i.e., the reactant gas in the cloud phase at $H_{1}$ is the mixture of the gas coming from the descending continuous phase and from the continuous phase in the second zone. Then, the calculation proceeds by the step wise method. Assumption of $C_{e}$ at $H_{1}$ and calculation are iterated until the value of right hand side of Eq. (7) near $\mathrm{H}_{2}$ approaches zero, since the left hand side of Eq. (7) must be zero at $H_{2}$ because $Q_{e}$ is zero at $H_{2}$.

4) The fourth zone The differential equations are the same as Eqs. (7), (8) and (9) except $Q_{e}$ is positive.

The integration of the differential equations were performed by Runge-Kutta method using FACOM 230-60 at data processing center, Kyoto University.

\subsection{Behaviour of bubble flow}

To solve the differential equations, various information about bubble behaviour is necessary.

The height of formation of the first bubble $H_{b 0}$, the diameter and frequency of the first bubble, the changes in diameter and frequency of the bubble along the bed height and the change in the gas flow rate as bubbles $Q_{b}$ along the bed height can be calculated by the method of previous paper $^{35}$ using the diameter and number of the holes of the perforated plate, the minimum fluidisation velocity, and the total gas flow rate $Q_{T}$. The change in the gas flow rate as clouds $Q_{c}$ and that of the gas flow rate through the continuous phase $Q_{e}$ along the bed height can be obtained as follows. 


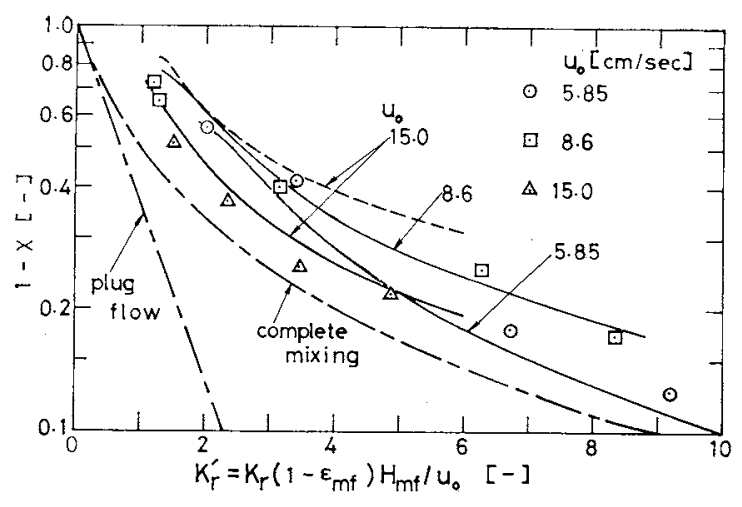

Calculation of model was carried out by putting $\gamma_{p}=0.0$. Broken curve shows the calculated result for $u_{0}=15.0$ $\mathrm{cm} / \mathrm{sec}$ taken gas flow rate as bubbles $Q_{b}=Q_{T}-Q_{m f}$

Fig. 3 Comparison between conversions obtained by experiments and calculations

Table $4 H_{b 0}, H_{1}, H_{2}$ and degree of deviation of actual gas flow rate as bubbles from that predicted by the two phase theory ${ }^{36)}$

\begin{tabular}{cccccc}
$\begin{array}{c}u_{o} \\
{[\mathrm{~cm} / \mathrm{sec}]}\end{array}$ & $\begin{array}{c}u_{0} / u_{m f} \\
{[-]}\end{array}$ & $\begin{array}{c}H_{b 0} \\
{[\mathrm{~cm}]}\end{array}$ & $\begin{array}{c}H_{1} \\
{[\mathrm{~cm}]}\end{array}$ & $\begin{array}{c}H_{2} \\
{[\mathrm{~cm}]}\end{array}$ & $\begin{array}{c}\left(Q_{T}-Q_{m f}\right) \\
-Q_{b} \\
{[\mathrm{cc} / \mathrm{sec}]}\end{array}$ \\
\hline 5.85 & 2.38 & 1.50 & 1.50 & 1.50 & 0.0 \\
8.6 & 3.50 & 1.89 & 1.89 & 1.89 & 0.0 \\
15.0 & 6.10 & 2.43 & 3.66 & 4.40 & $20.9^{*}$ \\
\hline$* \quad\left(Q_{T}-Q_{m f}\right)-Q_{b}$ & at the bottom of bed & \\
\hline
\end{tabular}

The cloud size is calculated by Murray's cloud ${ }^{25)}$. Since it is not circular, a cloud diameter equivalent to a circle $d_{c}$ was numerically calculated and following correlation was obtained.

$$
d_{c} / d_{b}=\sqrt{\alpha /(\alpha-1)}
$$

Then the ratio of the cloud volume to the bubble volume $\beta$ is given by

$$
\beta=1 /(\alpha-1)
$$

where $\alpha$ is determined by using bubble velocity $u_{b}$ deduced from the experiment of the two dimensional bed (Eq. (12)).

$$
u_{b}=0.73 \sqrt{g d_{b}}
$$

From $\beta, \varepsilon_{m f}$ and $Q_{b}$, the gas flow rates as clouds $Q_{c}$ and that through the continuous phase $Q_{e}$ can be calculated by

$$
\begin{aligned}
& Q_{c}=\beta \varepsilon_{m f} Q_{b} \\
& Q_{e}=Q_{T}-Q_{b}-Q_{e}
\end{aligned}
$$

The volume fraction of bubbles in the bed $\delta_{b}$ is given by

$$
\delta_{b}=Q_{b} / u_{b} A
$$

From these equations, the heights $H_{1}$ and $H_{2}$ are also calculated.

2.3 Gas interchange coefficient

1) $K_{b c}, K_{b c}$ is given by

$$
K_{b c}=K_{b c}^{b}+K_{b c}^{d}
$$

$K_{b c}^{b}$ represents the contribution of the gas circulation between the bubble and the cloud and is given by using the Murray's equation ${ }^{25}$.

$$
K_{b c}^{b}=4 u_{m f}^{\prime} / \pi d_{b}
$$

$K_{b c}^{d}$ shows the contribution of diffusion. The gas interchange coefficient based on the surface of the three dimensional bubble proposed by Davidson and Harrison $^{9)}$ was converted to the two dimensional bubble $^{19}$ and was further rewritten as the bubble volume base.

$$
K_{b e}^{d}=3.42 D_{G}^{1 / 2} g^{1 / 4} / d_{b}^{5 / 4}
$$

2) $K_{c e} \quad K_{c e}$ is composed of three terms.

$$
K_{c e}=K_{c e}^{d}+K_{c e}^{s}+K_{c e}^{c}
$$

$K_{c e}^{d}, K_{c e}^{s}$ and $K_{c e}^{c}$ are the contributions of diffusion, shedding of the cloud and coalescence of the bubble, respectively. $K_{o c}^{d}$ is calculated by converting Eq. (22) of the reference ${ }^{32)}$ to the bubble volume base. $K_{c e}^{s}$ is also calculated by the method of the reference ${ }^{32}$. But, since the calculation is very complicated, the result of $k_{c e}^{s}$ for glass beads $80-100^{\#} \quad\left(u_{m f}=2.25\right.$ $\mathrm{cm} / \mathrm{sec}$ ) is used by approximating the following equation.

$$
k_{c e}^{s}=0.18+0.032 d_{b}
$$

$K_{c e}^{c}$ is a function of change in the bubble frequency along the bed height and is given by the method of the reference ${ }^{33)}$. The curve for $K / d_{b}^{2}$ in Fig. 4 of the the reference ${ }^{33}$ is approximated by the following equation as a function of $\alpha$.

$$
K / d_{b}^{2}=(1.82 \alpha)^{-0.708} \quad \alpha>1
$$

\section{Discussion}

The experimental results of $1-\chi$ shown in Table 3 are replotted in Fig. 3 against $K_{r}^{\prime}$. The predicted results from the plug flow and the complete mixing models, and those calculated from the model $\left(\gamma_{p}=0\right)$ are also shown in the figure. $H_{b 0}, H_{1}, H_{2}$ and the degree of deviation of the actual gas flow rate as bubbles from that predicted by the two phase theory ${ }^{36}$ ) are shown in Table 4.

The experimental results can be explained not by the plug flow and complete mixing theories, but by the calculated results from the model. With the same $K_{r}^{\prime}$, the experimental conversion decreases with the increase in the gas velocity for the cases of $u_{0}=5.85$ and $8.6 \mathrm{~cm} / \mathrm{sec}$. But for the case of $u_{0}=15.0 \mathrm{~cm} / \mathrm{sec}$, the conversion is higher than that for the case of the other gas velocities at low $K_{r}^{\prime}$. These features are well reproduced by the calculated curves. The peculiarity for the case of $u_{0}=15.0 \mathrm{~cm} / \mathrm{sec}$ is caused by the deviation of the actual gas flow rate as bubbles from that predicted by the two phase theory ${ }^{36}$ ) as shown in Table 4, i.e., the flow rate of the gas in the continuous phase is higher than $Q_{m f}$. As shown in Fig. 3 by a broken curve, this peculiarity can not be explained by 
Table 5 Effect of parameters included in model on conversion and apparent first order chemical reaction rate constant

\begin{tabular}{|c|c|c|c|c|c|c|c|c|c|}
\hline & \multicolumn{3}{|c|}{$u_{0}=5.85 \mathrm{~cm} / \mathrm{sec}$} & \multicolumn{3}{|c|}{$u_{o}=8.6 \mathrm{~cm} / \mathrm{sec}$} & \multicolumn{3}{|c|}{$u_{0}=15.0 \mathrm{~cm} / \mathrm{sec}$} \\
\hline & $\begin{array}{l}\chi_{10}^{*} \\
{[-]}\end{array}$ & $\begin{array}{c}\Delta K_{5}^{* *} \\
{[-]}\end{array}$ & $\begin{array}{c}\Delta K_{10}^{* * *} \\
{[-]}\end{array}$ & $\begin{array}{l}\chi_{10} \\
{[-]}\end{array}$ & $\begin{array}{c}\Delta K_{5} \\
{[-]}\end{array}$ & $\begin{array}{r}\Delta K_{10} \\
{[-]}\end{array}$ & $\begin{array}{l}\chi_{10} \\
{[-]}\end{array}$ & $\begin{array}{l}\Delta K_{5} \\
{[-]}\end{array}$ & $\begin{array}{r}\Delta K_{10} \\
{[-]}\end{array}$ \\
\hline standard value & 0.923 & $\begin{array}{l}K_{\text {ras }} \\
=2.33\end{array}$ & $\begin{array}{l}K_{r a s} \\
=1.27\end{array}$ & 0.819 & $\begin{array}{l}K_{\text {ras }} \\
=2.66\end{array}$ & $\begin{array}{l}K_{\text {ras }} \\
=1.29\end{array}$ & 0.773 & $\begin{array}{l}K_{\text {ras }} \\
=4.69\end{array}$ & $\begin{array}{l}K_{\text {ras }} \\
=1.95\end{array}$ \\
\hline$Q_{b}=Q_{T}-Q_{m f}$ & - & - & - & - & - & - & 0.648 & -0.263 & -0.182 \\
\hline$\gamma_{p}=0.01$ & 0.926 & +0.0248 & +0.0377 & 0.827 & +0.0308 & +0.0502 & 0.781 & +0.0287 & +0.0532 \\
\hline$K_{b c}=0$ & 0.421 & -1.0 & -1.0 & 0.286 & -1.0 & -1.0 & 0.301 & -0.935 & -1.0 \\
\hline$K_{b c}^{d}=0$ & 0.753 & -0.572 & -0.578 & 0.608 & -0.553 & -0.568 & 0.631 & -0.389 & -0.463 \\
\hline$K_{b c}^{b}=0$ & 0.912 & -0.0696 & -0.0821 & 0.796 & -0.0883 & -0.104 & 0.715 & -0.174 & -0.187 \\
\hline$K_{b c}^{d}=0,2 K_{b c}^{b}$ & 0.848 & -0.335 & -0.336 & 0.722 & -0.305 & -0.313 & 0.735 & -0.121 & -0.167 \\
\hline$K_{b c}=\infty$ & 0.967 & +0.431 & +0.511 & 0.910 & +0.498 & +0.609 & 0.871 & +0.563 & +0.775 \\
\hline$K_{c e}=0$ & 0.763 & -0.587 & -0.554 & 0.649 & -0.517 & -0.492 & 0.712 & -0.240 & -0.318 \\
\hline$K_{c e}^{d}=0$ & 0.866 & -0.309 & -0.324 & 0.766 & -0.214 & -0.243 & 0.759 & -0.0521 & -0.105 \\
\hline$K_{c e}^{s}=0$ & 0.917 & -0.0442 & -0.0531 & 0.811 & -0.0345 & -0.0475 & 0.769 & -0.0131 & -0.0288 \\
\hline$K_{e e}^{c}=0$ & 0.902 & -0.116 & -0.0877 & 0.783 & -0.138 & -0.104 & 0.748 & -0.111 & -0.115 \\
\hline
\end{tabular}

${ }^{*} \chi$ at $H_{m f}=10.0 \mathrm{~cm}, * * \Delta K$ at $H_{m f}=5.0 \mathrm{~cm}, * * * \Delta K$ at $H_{m f}=10.0 \mathrm{~cm}$.

the model based on the two phase theory.

Since the model was promising, the effect of the individual parameter included in the model on the reaction performance was investigated.

The conversion and the local apparent reaction rate constant $K_{r a}$ calculated by the model were taken as the standard values for comparison and compared with those calculated by excluding a parameter, such as the gas interchange coefficient, from or adding a parameter, such as the volume fraction of the particles in a bubble, into the model.

The results are shown in Table 5. $K_{r a}$ is defined by

$$
u_{0} d C_{\mathrm{H}_{2}} / d H_{m f}=-K_{r a}\left(1-\varepsilon_{m f}\right) C_{\mathrm{H}_{2}}
$$

$\Delta K$ in Table 5 is defined by

$$
\Delta K=\left(K_{r a} / K_{r a s}\right)-1
$$

$K_{r a s}$ represents the standard value of $K_{r a}$ and is distinguished from $K_{r a}$ for the case of a parameter excluded or added.

From Table 5, the following are deduced.

1) $K_{r a}$ is far smaller than the true reaction rate constant $K_{r}=13.11 / \mathrm{sec}$.

2) $K_{r a}$ decreases significantly with the increase of $H_{m f}$. This indicates that care must be taken for calculating the conversion by using a representative bubble diameter for the case of rapid chemical reaction at low $H_{m f}$.

3) As known from the result for the case of $\gamma_{p}=$ $0.01^{11,13,30)}$, the effect of $\gamma_{p}$ increases with the increase of $H_{m f}$. However, the present chemical reaction is not so fast that the effect becomes significant.

4) For the case of $u_{0}=15.0 \mathrm{~cm} / \mathrm{sec}$, the conversion calculated by assuming the two phase theory decreases considerably.

5) The importance of $K_{b c}$ is known from the result of $K_{b c}=0$, since $K_{r a}$ is almost zero at both heights $H_{m f}=5$ and $10 \mathrm{~cm}$. The contribution of the diffusion term $K_{b c}^{d}$ is greater than that of the circulating flow term $K_{b c}^{b}$. Even if is used $2 \times K_{b c}^{b}$ which is obtained from the gas velocity of circulation in the Davidson's cloud $^{8)}$ verified by the recent experiment ${ }^{26)}$, the significant change does not appear under the present experimental conditions.

Since the conversion and $K_{r a}$ for the case of $K_{b e}=\infty$ are far greater than the standard values, the resistance of the gas exchange between the bubble and cloud phases can not be neglected.

6) The importance of $K_{c e}$ is also known from the result of $K_{c e}=0$. Among the three terms, the contribution of $K_{c e}^{s}$ is less important. The effect of $K_{c e}^{d}$ is the most significant for the case of $u_{0}=5.85$ and 8.6 $\mathrm{cm} / \mathrm{sec}$. Whereas, $K_{c e}^{c}$ is, for $u_{0}=15.0 \mathrm{~cm} / \mathrm{sec}$. The contribution of $K_{c e}^{e}$ for $K_{r a}$ decreases with the increase of $H_{m f}$.

Finally, a comment is made on the gas interchange between the jet and the continuous phase. Behie et $a l^{1,2)}$ reported very large value of the gas interchange coefficient based on the surface of the jet. Using the value $1,000 \mathrm{~kg} / \mathrm{m}^{2} \cdot \mathrm{hr}$ obtained by the extraporation of data beyond their experimental condition to the present one, the conversion at $H_{b 0}$ was calculated. For example, the calculated conversion 0.63 for the case of $u_{o}=15.0 \mathrm{~cm} / \mathrm{sec}\left(K_{r}^{\prime}=1.2\right)$ is too high compared with the experimental one (see Table 3 ). This may be due to the fact that the present experimental condition differed greatly from that of Behie et al., i.e., the size of the present jet was far smaller than theirs.

\section{Conclusion}

Experiments of hydrogenation of ethylene by palladium catalyst were carried out in a two dimensional fluidised bed with a perforated plate and the experimental result of the hydrogen conversion was compared with that predicted by the so-called "coalescence 
model". Consistency of experimental and calculated results was fairly good. Furthermore, the contribution of each parameter included in the model to the conversion and the apparent reaction rate was investigated. From this investigation, some suggestions were obtained for future works. Among those, the following may be important.

1) At the bottom of the two dimensional bed, the two phase theory is not always applicable. How is it in the three dimensional fluidised bed?

2) The contribution of the gas interchange between the cloud and bubble phases to the performance of the rapid catalytic chemical reaction is more important than that between the cloud and continuous phasés. Up to the present, no measured value of the overall gas interchange coefficient between the bubble and continuous phases has been separated into $K_{b c}$ and $K_{c e}$

3) Although the gas interchange between the jet and continuouse phases was not taken into account in this paper, it must be important in the case of high gas flow rate as pointed out by Behie et al. ${ }^{1,2)}$ and Zenz ${ }^{38)}$.

\section{Acknowledgment}

The authors are grateful to Professor Shigeaki Kasaoka of Okayama University for his helpful discussions about the chemical reaction system and the catalyst employed.

\section{Nomenclature}

$A \quad=$ cross sectional area of bed

$C_{\mathrm{H}_{2}}, C_{\mathrm{C}_{2} \mathrm{H}_{4}}$ and $C_{\mathrm{N}_{2}}=$ concentrations of $\mathrm{H}_{2}, \mathrm{C}_{2} \mathrm{H}_{4}$, and $\mathrm{N}_{2}$ gas, respectively [moles/cc] or [-]

$C_{b}, C_{c}$ and $C_{e}=$ concentrations of reactant gas in bubble, cloud and continuous phases, respectively [moles/cc] or [-]

$C_{i n} \quad=$ concentration of reactant gas at inlet $\quad[-]$

$D_{G} \quad=$ diffusion coefficient of reactant gas $\quad\left[\mathrm{cm}^{2} / \mathrm{sec}\right]$

$d_{b} \quad=$ bubble diameter $\quad[\mathrm{cm}]$

$\begin{array}{lll}d_{c} & =\text { cloud diameter } & {[\mathrm{cm}]}\end{array}$

$g \quad=$ gravitational acceleration $\quad\left[\mathrm{cm} / \mathrm{sec}^{2}\right]$

$H_{1}$ and $H_{2}=$ heights defined in section 2 [cm]

$H_{60} \quad=$ height of formation of the first bubble [cm]

$H_{m f} \quad=$ bed height at minimum fluidisation [cm]

$h \quad=$ height from distributor $\quad$ [cm]

$K \quad=$ amount of gas discharged from cloud by a coalescence of bubble

$\left[\mathrm{cm}^{2}\right]$

$K_{b e} \quad=$ gas interchange coefficient between bubble and continuous phases based on bubble volume

$K_{b c} \quad=$ gas interchange coefficient between bubble and cloud phases based on bubble volume

$K_{b c}^{b}$ and $K_{b c}^{d}=$ contributions of circulation and diffusion of gas to $K_{b G}$, respectively

$K_{c e} \quad=$ gas interchange coefficient between cloud and continuous phases based on bubble

volume

$[1 / \mathrm{sec}]$

$K_{e e}^{c}, K_{e e}^{d}$ and $K_{e e}^{s}=$ contributions of coalescence of bubble, diffusion, and shedding of cloud to $K_{c e}$, respectively

$[1 / \mathrm{sec}]$ $k_{c e}^{s} \quad=$ gas interchange coefficient between cloud and continuous phases based on surface of bubble caused by shedding of cloud $\quad[\mathrm{cm} / \mathrm{sec}]$

$K_{r} \quad=k_{r l} o_{p} \quad$ rate constant for first order chemical reaction based on volume of solids $\quad[1 / \mathrm{sec}]$

$K_{r}^{\prime} \quad=$ dimensionless reaction rate group defined by $K_{r}\left(1-\varepsilon_{m f}\right) H_{m f} / u_{0}$

$K_{r a} \quad=$ local apparent first order chemical reaction rate constant defined by Eq. (22) [1/sec]

$K_{\text {ras }} \quad=K_{r a}$ for standard value $\quad[1 / \mathrm{sec}]$

$\Delta K=$ defined by Eq. (23)

$k_{r} \quad=$ rate constant for first order chemical reaction based on weight of solids

[cc/sec $\cdot \mathrm{g}$-cat]

$Q_{b}, Q_{c}$ and $Q_{e}=$ gas flow rates as bubbles, as clouds and through continuous phase, respectively $[\mathrm{cc} / \mathrm{sec}]$

$Q_{m f} \quad=$ gas flow rate at minimum fluidisation $\quad[\mathrm{cc} / \mathrm{sec}]$

$Q_{T} \quad=$ total gas flow rate [cc/sec]

$r \quad=$ chemical reaction rate $\quad[\mathrm{cc} / \mathrm{sec} \cdot \mathrm{g}-\mathrm{cat}]$

$t \quad=$ temperature $\quad\left[{ }^{\circ} \mathrm{C}\right]$

$u_{0} \quad=$ superficial gas velocity $\quad[\mathrm{cm} / \mathrm{sec}]$

$\begin{array}{lll}u_{b} & =\text { rising velocity of bubble } \quad[\mathrm{cm} / \mathrm{sec}]\end{array}$

$u_{m f} \quad=$ minimum fluidisation gas velocity $\quad[\mathrm{cm} / \mathrm{sec}]$

$\left.\begin{array}{ll}u_{m f}{ }^{\prime} & =\left(Q_{T}-Q_{b}\right) / A\end{array}\right][\mathrm{cm} / \mathrm{sec}]$

$W \quad=$ weight of catalyst $\quad[\mathrm{g}]$

$\alpha \quad=u_{b} \varepsilon_{m f} / u_{m f}$ or $u_{b} \varepsilon_{m f} / u_{m f}^{\prime}$

$\beta \quad=$ ratio of cloud volume to bubble volume $\quad$ [-]

$\gamma_{p} \quad=$ volume fraction of solids in bubble $\quad[-]$

$\delta_{b} \quad=$ fraction of bubble phase in bed $\quad[-]$

$\varepsilon_{m f} \quad=\begin{aligned} & \text { voidage fraction of bed at minimum } \\ & \text { fluidisation }\end{aligned}$

$\rho_{p} \quad=$ density of particles $\quad[\mathrm{g} / \mathrm{cc}]$

$\chi \quad=$ conversion of reactant gas

\section{Literature Cited}

1) Behie, L. A. and P. Kehoe: AIChE J., 19, 1070 (1973).

2) Behie, L. A., M. A. Bergougnou and C. G. J. Baker: Preprint of Internat. Fluidization Conf., Pacific Grove, California, June, III-34 (1975).

3) Botton, R. J.: Chem. Eng. Progr. Symp. Ser. No. 101, 66, 8 (1970).

4) Calderbank, P. H. and F. D. Toor: "Fluidization", ed. by Davidson and Harrison, p. 383, Academic Press (1971).

5) Chiba, T. and K. Terashima and H. Kobayashi: Chem. Eng. Sci., 27, 965 (1972).

6) Chiba, T. and H. Kobayashi: Proc. Int. Symp. "Fluidization and its Applications", Toulouse, Oct., 1973, p. 468, Société de Chimie Industrelle (1974).

7) Cooke, M. J., W. Harris, J. Highley and D. F. Williams: Symp. on Fluidization. I, Tripartite Chem. Eng. Conf. Montreal, Sept., p. 14 (1968).

8) Davidson, J. F.: Trans. Inst. Chem. Engrs., (London), 39, 230 (1961).

9) Davidson, J. F. and D. Harrison: "Fluidised Particles", p. 97, Cambridge Univ. Press (1963).

10) Fryer, C. and O. E. Potter: Ind. Eng. Chem., Fundam., 11, 338 (1972).

11) Hiraki, I., K. Yoshida and D. Kunii: Kagaku Kōgaku, 29, 846 (1965).

12) Kato, K. and C. Y. Wen: Chem. Eng. Sci., 24, 1351 (1969).

13) Kobayashi, H., F. Arai and T. Chiba: Kagaku Kōgaku, 29, 858 (1965).

14) Kobayashi, H., F. Arai, T. Chiba and Y. Tanaka: ibid., 33, 274 (1969). 
15) Kobayashi, H., F. Arai, T. Chiba, Y. Tanaka and M. Matsui: ibid., 33, 675 (1969).

16) Kunii, D. and O. Levenspiel: Ind. Eng. Chem., Fundam., 7, 446 (1968).

17) Kunii, D. and O. Levenspiel: Ind. Eng. Chem., Process Des. Dev., 7, 481 (1969).

18) Kunii, D. and O. Levenspiel: "Fluidization Engineering", p. 108, John Wiley and Sons (1969).

19) Matsuno, Y. and T. Okuda: Asahi Garasu Kogyo Gijutsu Shoreikai Kenkyu Hokoku, 22, 303 (1973).

20) Miwa, K., S. Mori, T. Kato and I. Muchi: Kagaku Kögaku, 35, 770 (1971).

21) Miwa, K., S. Mori and I. Muchi: ibid., 37, 295 (1973).

22) Mori, S. and I. Muchi: ibid., 34, 510 (1970).

23) Mori, S. and C. Y. Wen: AIChE J., 11, 109 (1975).

24) Mori, S. and C. Y. Wen: Preprint of Internat. Fluidization Conf., Pacific Grove, California, June, III-5 (1975).

25) Murray, J. D.: J. Fluid. Mech., 22, 57 (1965).

26) Nguyen, X. T., L. S. Leung and R. H. Weiland: Preprint of Internat. Fluidization Conf., Pacific Grove, California, June, III-54 (1975).

27) Orcutt, J. C., J. F. Davidson and R. L. Pigford: Chem.
Eng. Progr. Symp. Ser. No. 38, 58, 1 (1962).

28) Partridge, B. A. and P. N. Rowe: Trans. Instn. Chem. Engrs. (London), 44, T335 (1966).

29) Schit, G. C. A. and L. L. von Reijen: Adv. Catalysis, 10, 242 (1958).

30) Toei, R., R. Matsuno, H. Kojima, Y. Nagai, K. Nakagawa and S. Yu: Kagaku Kögaku, 29, 851 (1965).

31) Toei, R., R. Matsuno and I. Fujiki: ibid., 31, 398 (1967).

32) Toei, R., R. Matsuno, H. Miyagawa, K. Nishitani and $Y$. Komagawa: ibid., 32, 565 (1968).

33) Toei, R., R. Matsuno, K. Nishitani, H. Hayashi and T. Imamoto: ibid., 33, 668 (1969).

34) Toei, R., R. Matsuno, M. Oichi, M. Kagizaki and R. Tsukada: Kagaku Kogaku Ronbunshu, 1, 565 (1975).

35) Toei, R., R. Matsuno, M. Oichi, K. Kubo and T. Yanagida: ibid., 1, 571 (1975).

36) Toomey, R. D. and H. F. Johnstone: Chem. Eng. Progr., 48, 220 (1952).

37) Toor, F. D. and P. H. Calderbank: Proc. Int. Symp. on Fluidization, Netherland Univ. Press, p. 373 (1967).

38) Zenz, F. A.: Symp. on Fluidization. II, Tripartite Chem. Eng. Conf. Montreal, Sept., p. 36 (1968).

\title{
VELOCITY PROFILE AND TEMPERATURE DISTRIBU- TION IN THE HORIZONTAL EPITAXIAL REACTOR
}

\author{
Tamotsu HANZAWA, KazUo SAKAUCHI, Kunio KATO \\ AND TEIRIKI TADAKI \\ Department of Chemical Engineering, Gunma University, Kiryu 376
}

\begin{abstract}
The cross-sectional and axial velocity profiles and temperature distributions in a horizontal epitaxial reactor were calculated numerically from fundamental equations under certain assumptions. Streamlines in the cross-section showed similar pattern over the whole range of $G r$, but the value of stream function was affected by $G r$. The axial velocity profiles were quite different from that of parabolic flow when $G r$ was larger than $10^{4}$. The temperature distributions in a cross-section of the channel became uniform when Gr was large.

In order to check the calculated results, the axial velocity profile and the temperature distribution were measured in this reactor under the same conditions as those of this calculation. The calculated velocity and temperature were a good approximation of the experimental ones.
\end{abstract}

\section{Introduction}

The epitaxial reactor (chemical vapor deposition reactor) has been widely used for production of semiconductor high purity crystals and dielectric films, and for the treatment of material surface. This reactor has been recently used for the treatment of sensitive film surface in photographic technology.

In an epitaxial reactor, a susceptor heated up in

Received November 22, 1976. Correspondence concerning this article should be addressed to T. Hanzawa. T. Tadaki is at Dept. of Chem. Eng., Tohoku Univ., Sendai 980. $700-1200^{\circ} \mathrm{C}$ is placed at the bottom in the channel, and vigorous three-dimensional free convective flow is generated by the buoyancy force induced by a large temperature difference. This phenomenon is pronounced in a horizontal epitaxial reactor, which has been generally used. Therefore, velocity distributions are not easily calculated from fundamental equations, and only temperature distributions have been investigated experimentally ${ }^{2,6,10)}$.

Recently, along with the remarkable development of electronic computers, a few numerical solutions have been obtained for the three-dimensional laminar 